\title{
A Rational Strategy for Maintenance of Low Volume Road Network
}

\author{
P. K. Agarwal ${ }^{1} \cdot$ S. Choudhary ${ }^{1}$ A. B. Khan ${ }^{1}$
}

Received: 30 September 2015/Accepted: 11 August 2016/Published online: 30 August 2016

(c) Springer International Publishing Switzerland 2016

\begin{abstract}
Low volume roads deteriorates fast due to lack of timely maintenance, leading to higher vehicle operating costs, increasing number of accidents, etc. Once these roads start to deteriorate; they deteriorate rapidly and require more resources for effective maintenance. Thus, providing appropriate maintenance treatment at appropriate time, the rate of deterioration can be deferred to a great extent and this will reduce the maintenance cost of huge low volume road network in developing countries like India. Prioritization of maintenance activities depends on several factors such as functional condition, structural condition and importance of sections in the road network. However, a critical review of the literature indicated that no such comprehensive methodology is available to prioritize maintenance activities for a low volume road network. Thus, the main objective of this study is to develop a strategy to select the most appropriate activities to be carried out at different sections considering their priority for maintenance based on importance, conditions of road section, etc. In this study, a two stage maintenance strategy is proposed. Stage I consist of a strategy to determine maintenance priority of low volume road section and stage II consist of a strategy to determine priority of maintenance activities to be carried out on identified low volume road sections. The strategy proposes that first sections which are more critical for maintenance needs to be selected in stageI. Further, the sections identified in stage I needs to be evaluated in more detailed so that the various maintenance activities to be carried out on these sections can be
\end{abstract}

\section{P. K. Agarwal}

pka9@yahoo.com

1 Department of Civil Engineering, Maulana Azad National Institute of Technology, Bhopal 462051, India prioritized. Thus, the proposed strategy is less time consuming simple and cost effective and can be executed with minimal data which can be obtained easily and economically from each section of a low volume roads network.

Keywords Low volume roads · Rural road network · Road maintenance $\cdot$ Prioritization - Maintenance activity

\section{Introduction}

A huge rural road network created recently in India has resulted in increased social and economic benefits in rural areas. However, these benefits would reduce substantially due to poor maintenance of these created assets [1]. Thus, in order to reap the benefits of created assets it is essential to maintain the low volume rural road network timely. However, experiences have shown that these roads, although relatively cheap to construct, are often an unsustainable maintenance burden for many rural road authorities, and are rarely maintained in a serviceable conditions [2]. Rural road network consists of the $58 \%$ road network percentage of total road network in India, hence required a great care and huge investment for construction and maintenance. Hence, low volume roads are deteriorating fast due to lack of timely maintenance, leading to higher vehicle operating costs, increasing number of accidents, etc. Once these roads start to deteriorate; they deteriorate rapidly beyond the point where maintenance is effective [3]. If timely maintenance is not provided, the reconstruction will become unavoidable. Thus, providing appropriate maintenance treatment at appropriate time, the rate of deterioration can be deferred to a great extent and this will reduce the maintenance cost of such a huge road network. Thus, prioritization of maintenance of 
the low volume rural roads is essential. Prioritization of maintenance activities depends on several factors such as present condition of road i.e. quantity and quality of deterioration, increasing rate of deterioration, importance of the different sections, etc. [4]. Hence, it is difficult to select various activities in order of their maintenance priority in a road network. Thus, there is an urgent need to develop a rational strategy for priority of maintenance activities to be carried out in a low volume road network.

However, a critical review of the literature [5-7] indicated that no such comprehensive strategy is available to prioritize maintenance activities for a low volume road network. Most of the methods for evaluation of section conditions are sophisticated, costly and need specialized equipment and operators [8]. Thus, the use of such methodology on rural network practically becomes impossible. Hence, there is an urgent need to develop innovative strategies focusing on rural road network which are cost effective, quick and simply operated [9]. Thus, the main objective of this study is to develop a strategy to select the most appropriate activities to be carried out at different sections of a low volume roads network considering their priority for maintenance based on importance, functional and structural conditions of road section, etc. In this study, a two stage maintenance strategy is proposed. The strategy proposed in this study is illustrated with the help of example of a hypothetical rural road network. Analysis results indicated that the proposed strategy is considered to be more rational, innovative and logical.

This paper consists of four sections of which this is the first. The second section presents proposed strategy for maintenance of rural road network and the third section present the analysis and result using proposed strategy. The last section presents the important conclusions drawn based on this study.

\section{Proposed Strategy for Maintenance of Rural Road Network}

The main objective of this study is to develop the maintenance strategy for rural roads network. It is proposed to select maintenance activities to be carried out on different rural road sections in two stages. Stage I determines rural road section priority based on the basis of the strategy proposed in this study. Stage II determines priority of activities on different sections. Thus, the strategy proposes that first sections which are more critical for maintenance needs to be selected. The strategy identifies to select maintenance activities using minimal data. Further, strategy proposes that the sections identified in stage I needs to be evaluated in more details so that the various maintenance activities to be carried out on these sections can be prioritized. Thus, the proposed strategy will be more economical as detailed studies needs not to be carried out on all the sections. The strategy to determine priority for stage I and stage II are briefly explained in the following section:

\section{Stage-I Strategy to Determine Maintenance Priority of Rural Road Sections}

A hierarchical structure is developed to identify the factors affecting the maintenance priority of rural road sections. The maintenance priority of rural road section depends upon sectional condition and sectional importance. Further sectional condition depends upon functional condition and structural condition and functional condition further depends upon traffic operational condition and traffic safety condition of rural roads. Figure 1 presents the hierarchical structure developed in stage I to determine maintenance priority of rural road sections.

The general equation for $\mathrm{PI}_{\mathrm{s}}$ is presented in Eq. 1 .

$P I_{s}=\sum_{i=1}^{n}\left(P F I_{i} \times w_{i}\right)$

where $\mathrm{PI}_{\mathrm{S}}=$ Priority index of section $\mathrm{SPFI}_{\mathrm{i}}=$ Priority factor index for factor $\mathrm{i}, \mathrm{W}_{\mathrm{i}}=$ Weight of priority factor $\mathrm{i}$, $\mathrm{n}=$ number of factor. Now various priority factors considered are structural condition, traffic operation condition, traffic safety condition and section importance. Hence, Eq. 1 can be written as follows:

$\mathrm{PI}_{\mathrm{s}}=\mathrm{W}_{\text {scis }} \times \mathrm{SCI}_{\mathrm{S}}+\mathrm{W}_{\text {Tois }} \times \mathrm{TOI}_{\mathrm{s}}+\mathrm{W}_{\text {Tsis }} \times \mathrm{TSI}_{\mathrm{s}}$ $+\mathrm{W}_{\text {siis }} \times \mathrm{SII}_{\mathrm{s}}$

where $\mathrm{SCI}_{\mathrm{s}}=$ Structural condition index for section $\mathrm{S}, \mathrm{STOI}_{\mathrm{S}}=$ Traffic operational condition index for section $\mathrm{S}, \quad \mathrm{TSI}_{\mathrm{s}}=$ Traffic safety condition index for section $\mathrm{S}, \quad \mathrm{SII}_{\mathrm{s}}=$ Section Importance index for section $\mathrm{S}$,

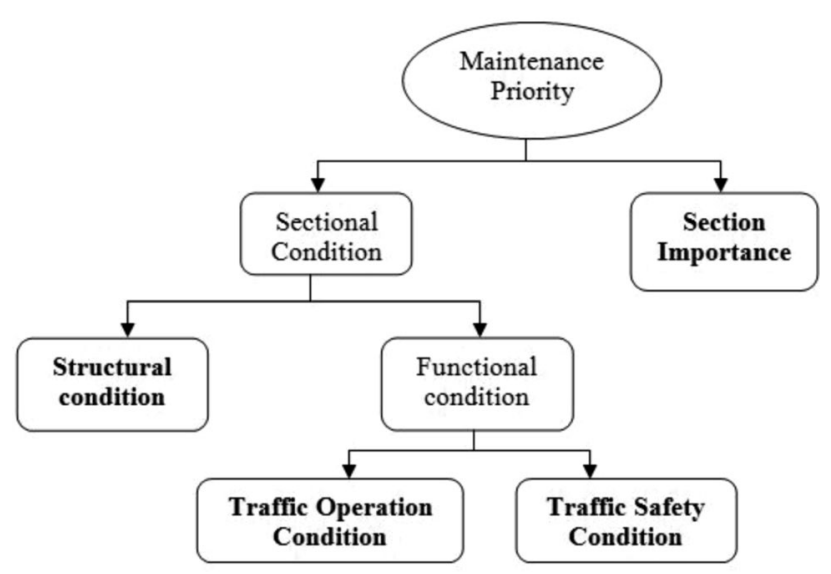

Fig. 1 A hierarchical structure for maintenance priority of rural road sections 
$\mathrm{W}_{\text {scis }}=$ Weight of structural condition for section $\mathrm{S}$, $\mathrm{W}_{\text {Tois }}=$ Weight of traffic operational condition for section $\mathrm{S}, \mathrm{W}_{\text {Tscs }}=$ Weight of traffic safety condition for section $\mathrm{S}$, $\mathrm{W}_{\text {siis }}=$ Weight of section importance for section S. Now, the strategy to evaluate condition of priority factors i.e. Traffic safety condition, Traffic operational condition, Structural Condition is developed and explained as follows.

\section{Traffic Safety Index $\left(\right.$ TSI $\left._{\mathbf{s}}\right)$}

It is proposed that condition of traffic safety can be evaluated using an index named as traffic safety index $\left(\mathrm{TSI}_{\mathrm{s}}\right)$. The $\mathrm{TSI}_{\mathrm{S}}$ can be obtained by a user defined rating. The rating for traffic safety conditions of a section may depends upon poor geometric condition of road, traffic furniture condition and poor surface condition, etc. Traffic safety index may vary from 0.0 to 1.0 . TSI $_{\mathrm{s}}$ may be rated as 1 under extremely hazardous condition i.e. extremely poor geometric condition, extremely poor traffic furniture condition, extremely poor surface condition, etc. Table 1 presents the guidelines for user rating of traffic safety condition.

Table 1 Guidelines for user rating for traffic safety condition

\begin{tabular}{lll}
\hline S. no. & Section safety condition & Rating \\
\hline 1 & Extremely hazardous condition & 1.0 \\
2 & Most severe condition & 0.8 \\
3 & Severe condition & 0.6 \\
4 & Moderate condition & 0.4 \\
5 & Safe condition & 0.2 \\
6 & No hazardous condition & 0.0 \\
\hline
\end{tabular}

Table 2 Guidelines for user rating for section importance index

\begin{tabular}{lll}
\hline S. no. & Section importance & Rating \\
\hline 1 & Extremely important & 1.0 \\
2 & Very important & 0.8 \\
3 & Fairly important & 0.6 \\
4 & Important & 0.4 \\
5 & Less important & 0.2 \\
6 & Very less important & 0.0 \\
\hline
\end{tabular}

Table 3 Details of weight of various priority factors

\begin{tabular}{lll}
\hline S. no. & Weight of priority factor & Weight value \\
\hline 1 & Traffic operational index $\left(\mathrm{W}_{\text {Tois }}\right)$ & 0.09 \\
2 & Traffic safety index $\left(\mathrm{W}_{\text {Tscs }}\right)$ & 0.17 \\
3 & Structural condition index $\left(\mathrm{W}_{\text {scis }}\right)$ & 0.31 \\
4 & Section importance index $\left(\mathrm{W}_{\text {siis }}\right)$ & 0.43 \\
& Total & 1.00 \\
\hline
\end{tabular}

Table 4 Strategy for evaluation of sub priority factor i at section $\mathrm{S}$ $\left(\mathrm{SFI}_{\mathrm{iS}}\right)$

Structural condition index $\left(\mathrm{SCI}_{\mathrm{s}}\right)$

A1 Structural Condition Index

$\mathrm{SCI}_{\mathrm{s}}=\left(\mathrm{ASD}_{\mathrm{s}}\right) / \mathrm{TAS}_{\mathrm{s}}$

Where,

$\mathrm{ASD}_{\mathrm{s}}=$ Area of structural distress at section $\mathrm{S}\left(\mathrm{m}^{2}\right)$

TAS $_{\mathrm{s}}=$ Total area of section at section $\mathrm{S}$ in $\left(\mathrm{m}^{2}\right)$

B Traffic operational Index (TOI $\left.{ }_{\mathrm{s}}\right)$

B1 Rutting surface index $\left(\mathrm{RSI}_{\mathrm{s}}\right)$

$\mathrm{RSI}_{\mathrm{s}}=\left(\mathrm{RSA}_{\mathrm{s}}\right) / \mathrm{TCA}_{\mathrm{s}}$

Where,

$\mathrm{RSA}_{\mathrm{s}}=$ Rutting surface area $\left(\mathrm{m}^{2}\right)$

TCA $=$ Total carriageway area $\left(\mathrm{m}^{2}\right)$

B2 Potholes surface index (PSIs)

$\mathrm{PSI}=\left(\mathrm{PSA}_{\mathrm{s}}\right) / \mathrm{TCA}_{\mathrm{s}}$

Where,

$\mathrm{PSA}_{\mathrm{s}}=$ Pothole surface area $\left(\mathrm{m}^{2}\right)$

TCA $=$ Total carriageway area $\left(\mathrm{m}^{2}\right)$

B3 Deep cut surface index (DCI)

$\mathrm{DCI}=(\mathrm{DCSA}) / \mathrm{TCA}_{\mathrm{s}}$

Where,

DCSA $=$ Length of cut surface $\times$ width of cut surface $\left(\mathrm{m}^{2}\right)$

$\mathrm{TCA}_{\mathrm{s}}=$ Total carriageway area $\left(\mathrm{m}^{2}\right)$

C Traffic safety index $\left(\mathrm{TSI}_{\mathrm{s}}\right)$

$\mathrm{C} 1$ Improper curve radius index (CRI)

$\mathrm{CRI}=(\mathrm{RCR}-\mathrm{ACR}) / \mathrm{ACR}$

Where,

$\mathrm{RCR}=$ Required curve radius $(\mathrm{m})$

$\mathrm{ACR}=$ Available curve radius $(\mathrm{m})$

C2 Traffic sign/marking index (TSMI)

TSMI $=($ RTSM - ATSM $) /$ RTSM

Where,

RTSM = Required number of traffic sign (number)

ATSM = Available number of traffic sign/Marking (number)

$\mathrm{C} 3$ Inadequate super elevation index $\left(\mathrm{SCI}_{\mathrm{CV}}\right)$

$\mathrm{SEI}_{\mathrm{CV}}=\left(\mathrm{RSE}_{\mathrm{CV}}-\mathrm{ASE}_{\mathrm{CV}}\right) / \mathrm{RSE}_{\mathrm{CV}}$

Where,

$\mathrm{RSE}_{\mathrm{CV}}=$ Required super elevation at curve location (\%)

$\mathrm{ASE}_{\mathrm{CV}}=$ Available super elevation at curve location (\%)

C4 Side Distance Index $\left(\mathrm{SDI}_{\mathrm{s}}\right)$

PSI $=$ PSA $/$ TCA

$\mathrm{SDI}_{\mathrm{s}}=\mathrm{RSA}-\mathrm{ASD} / \mathrm{RSDWhere}$,

$\mathrm{ASD}=$ Available Side Distance at intersection

RSD $=$ Required Side Distance at intersection

C5 Inadequate camber Condition index $\left(\mathrm{ICC}_{\mathrm{s}}\right)$

$\mathrm{ICC}_{\mathrm{s}}=\frac{\mathrm{RC}_{\mathrm{s}}-\mathrm{ACs}}{\mathrm{RCs}}$

Where,

$\mathrm{AC}_{\mathrm{s}}=$ Available camber in $\%$ at section $\mathrm{s}$

$\mathrm{RC}_{\mathrm{s}}=$ required camber in $\%$ at section $\mathrm{s}$ 
Table 5 Details of input data for analysis of stage-I

\begin{tabular}{|c|c|c|c|c|c|c|}
\hline S. no & Section & $\begin{array}{l}\text { Distress area of section } \\
\operatorname{DOS}_{\mathrm{s}}\left(\mathrm{m}^{2)}\right.\end{array}$ & $\begin{array}{l}\text { Total area of that section } \\
\text { TAS }_{\mathrm{s}}\left(\mathrm{m}^{2}\right)\end{array}$ & $\begin{array}{l}\text { Safety rating } \\
\text { index } \\
\mathrm{SRI}_{\mathrm{s}}\end{array}$ & $\begin{array}{l}\text { Area of structure distress } \\
\operatorname{ASD}_{\mathrm{s}}\left(\mathrm{m}^{2}\right)\end{array}$ & $\begin{array}{l}\text { Section importance } \\
\text { rating } \\
\mathrm{SII}_{\mathrm{s}}\end{array}$ \\
\hline 1 & $\mathrm{~S} 1$ & 300 & 3750 & 0.3 & 337.5 & 0.5 \\
\hline 2 & $\mathrm{~S} 2$ & 450 & 3750 & 0.4 & 487.5 & 0.3 \\
\hline 3 & $\mathrm{~S} 3$ & 150 & 3750 & 0.2 & 187.5 & 0.2 \\
\hline 4 & S4 & 375 & 3750 & 0.4 & 412.5 & 0.6 \\
\hline 5 & S5 & 225 & 3750 & 0.3 & 262.5 & 0.4 \\
\hline 6 & S6 & 675 & 3750 & 0.7 & 712.5 & 0.9 \\
\hline 7 & S7 & 825 & 3750 & 1 & 862.5 & 1 \\
\hline 8 & S8 & 525 & 3750 & 0.5 & 562.5 & 0.3 \\
\hline 9 & S9 & 750 & 3750 & 0.8 & 787.5 & 0.8 \\
\hline 10 & S10 & 600 & 3750 & 0.6 & 637.5 & 0.7 \\
\hline
\end{tabular}

Table 6 Analysis results for stage 1 (determination of section priority)

\begin{tabular}{|c|c|c|c|c|c|c|c|}
\hline $\begin{array}{l}\text { S. } \\
\text { no. }\end{array}$ & Section & $\begin{array}{l}\text { Traffic operational } \\
\text { index } \\
\text { TOI }_{\mathrm{s}}\end{array}$ & $\begin{array}{l}\text { Traffic safety } \\
\text { index } \\
\text { TSI }_{\mathrm{s}}\end{array}$ & $\begin{array}{l}\text { Structural condition } \\
\text { index } \\
\mathrm{SCI}_{\mathrm{s}}\end{array}$ & $\begin{array}{l}\text { Section importance } \\
\text { index } \\
\text { SII }_{\mathrm{s}}\end{array}$ & $\begin{array}{l}\text { Priority index of } \\
\text { section } \\
\mathrm{PI}_{\mathrm{s}}\end{array}$ & $\overline{\text { Rank }}$ \\
\hline 1 & $\mathrm{~S} 1$ & 0.11 & 0.3 & 0.13 & 0.5 & 0.3162 & 6 \\
\hline 2 & $\mathrm{~S} 2$ & 0.22 & 0.4 & 0.09 & 0.3 & 0.2447 & 9 \\
\hline 3 & $\mathrm{~S} 3$ & 0.04 & 0.2 & 0.05 & 0.2 & 0.1391 & 10 \\
\hline 4 & S4 & 0.18 & 0.4 & 0.20 & 0.6 & 0.4042 & 5 \\
\hline 5 & S5 & 0.20 & 0.3 & 0.23 & 0.4 & 0.3123 & 7 \\
\hline 6 & S6 & 0.09 & 0.7 & 0.16 & 0.9 & 0.5637 & 3 \\
\hline 7 & S7 & 0.22 & 1.0 & 0.23 & 1.0 & 0.6911 & 1 \\
\hline 8 & S8 & 0.15 & 0.5 & 0.19 & 0.3 & 0.2684 & 8 \\
\hline 9 & S9 & 0.19 & 0.8 & 0.22 & 0.8 & 0.5653 & 2 \\
\hline 10 & S10 & 0.13 & 0.6 & 0.12 & 0.7 & 0.4519 & 4 \\
\hline
\end{tabular}

\section{Traffic Operational Index $\left(\right.$ TOI $\left._{\mathrm{s}}\right)$}

It is proposed that condition of traffic operation can be evaluated using an index named as traffic operation index $\left(\mathrm{TOI}_{\mathrm{s}}\right)$. The surface distress affects the traffic operation. Hence, the general equation for $\mathrm{TOI}_{\mathrm{s}}$ is presented in Eq. 3 .

$\mathrm{TOI}_{\mathrm{s}}=\operatorname{DOS}_{\mathrm{s}} / \mathrm{TAS}_{\mathrm{s}}$

where $\mathrm{TOI}_{\mathrm{s}}=$ Traffic operational Index for section S.DOS $\mathrm{s}=$ Area of surface distress for section $\mathrm{S}$ $(\mathrm{m} 2) \mathrm{TAS}_{\mathrm{s}}=$ Total area of section S (m2).

\section{Structural Condition Index $\left(\mathbf{S C I}_{\mathrm{s}}\right)$}

It is proposed that structural condition can be evaluated using an index named as structural condition index $\left(\mathrm{SCI}_{\mathrm{s}}\right)$. The structural distress i.e. fatigue, cracking and rut depth effects structural condition. Hence, the general equation for $\mathrm{SCI}_{\mathrm{S}}$ is presented in Eq. 4

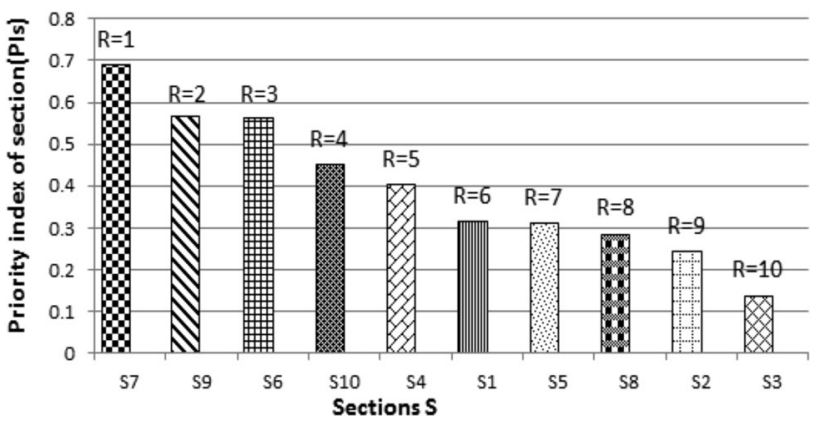

Fig. 2 Result for stage $\mathrm{I}-\mathrm{PI}_{\mathrm{s}}$ of different low volume rural road sections

$\mathrm{SCI}_{\mathrm{s}}=\left(\mathrm{ASD}_{\mathrm{s}}\right) / \mathrm{TAS}_{\mathrm{s}}$.

where $\mathrm{SCI}_{\mathrm{s}}=$ Structural condition index of section $\mathrm{SASD}_{\mathrm{s}}=$ Area of structural distress at section $\mathrm{S}\left(\mathrm{m}^{2}\right)$ $\operatorname{TAS}_{\mathrm{s}}=$ Total area of section $\mathrm{S}\left(\mathrm{m}^{2}\right)$. 
Table 7 Details of input data of activities on road sections

\begin{tabular}{lllllll}
\hline S. no. & Parameter & S7 & S9 & S6 & S10 & S4 \\
\hline 1 & ASD $_{\mathrm{s}}\left(\mathrm{m}^{2}\right)$ & 862.5 & 787.5 & 712.5 & 637.5 & 412.5 \\
2 & TAS $_{\mathrm{s}}\left(\mathrm{m}^{2}\right)$ & 3750 & 3750 & 3750 & 3750 & 3750 \\
3 & RSA & $375 \mathrm{~m}^{2}$ & $410 \mathrm{~m}^{2}$ & $450 \mathrm{~m}^{2}$ & $375 \mathrm{~m}^{2}$ & - \\
4 & PSA & $750 \mathrm{~m}^{2}$ & $610 \mathrm{~m}^{2}$ & $675 \mathrm{~m}^{2}$ & - & $637.5 \mathrm{~m}^{2}$ \\
5 & DCSA & $320 \mathrm{~m}^{2}$ & $330 \mathrm{~m}^{2}$ & - & - & $310 \mathrm{~m}^{2}$ \\
6 & RTSM & $12 \mathrm{no}^{2}$ & $10 \mathrm{no}$ & $10 \mathrm{no}$ & $11 \mathrm{no}$ & - \\
7 & ATSM & $4 \mathrm{no}$ & $5 \mathrm{no}$ & $3 \mathrm{no}$ & $4 \mathrm{no}$ & - \\
8 & RCR & $500 \mathrm{~m}$ & $480 \mathrm{~m}$ & - & $450 \mathrm{~m}$ & $450 \mathrm{~m}$ \\
9 & ACR & $370 \mathrm{~m}$ & $370 \mathrm{~m}$ & - & $330 \mathrm{~m}$ & $380 \mathrm{~m}$ \\
\hline
\end{tabular}

Table 8 Analysis results for $\mathrm{SF}_{\mathrm{is}}$ and $\mathrm{ME}_{\mathrm{as}}$ for different activities

\begin{tabular}{|c|c|c|c|c|c|c|}
\hline \multirow[t]{2}{*}{ S. no. } & \multirow[t]{2}{*}{ Section } & \multicolumn{2}{|l|}{ Individual sub priority factor indices } & \multirow[t]{2}{*}{ Activity } & & \multirow[t]{2}{*}{$\mathrm{ME}_{\mathrm{aS}}$} \\
\hline & & Name of sub priority factor indices & $\mathrm{SFI}_{\mathrm{iS}}$ & & & \\
\hline \multirow[t]{6}{*}{1} & \multirow[t]{6}{*}{ S7 } & Poor structural condition & 0.23 & Overlaying & $(\mathrm{A} 7-1)$ & 1.0 \\
\hline & & Rut depth index & 0.10 & Filling of rut depth & $(\mathrm{A} 7-2)$ & 0.3 \\
\hline & & Deep cuts surfaces & 0.08 & Repair of settled surface & $(\mathrm{A} 7-3)$ & 0.7 \\
\hline & & No proper sign boards & 0.67 & Placing of sign boards & $(\mathrm{A} 7-4)$ & 0.2 \\
\hline & & Pot hole index & 0.20 & Filling of potholes & $(\mathrm{A} 7-5)$ & 0.3 \\
\hline & & No proper curve & 0.26 & Providing proper curves & $(\mathrm{A} 7-6)$ & 0.5 \\
\hline \multirow[t]{7}{*}{2} & \multirow[t]{7}{*}{ S9 } & Poor structural condition & 0.22 & Overlaying & (A9-1) & 1.0 \\
\hline & & Rut depth index & 0.11 & Filling of rut depth & (A9-2) & 0.3 \\
\hline & & Pot hole index & 0.16 & Filling of potholes & (A9-3) & 0.3 \\
\hline & & Deep cuts surfaces & 0.09 & Repair of settled surface & (A9-4) & 0.4 \\
\hline & & No proper sign boards & 0.50 & Placing of sign boards & (A9-5) & 0.2 \\
\hline & & Pot hole index & 0.16 & Filling of potholes & (A9-6) & 0.2 \\
\hline & & No proper curve & 0.23 & Providing proper curves & (A9-7) & 0.6 \\
\hline \multirow[t]{5}{*}{3} & \multirow[t]{5}{*}{ S6 } & Poor structural condition & 0.16 & Overlaying & (A6-1) & 1.0 \\
\hline & & Rut depth index & 0.12 & Filling of rut depth & (A6-2) & 0.4 \\
\hline & & Pot hole index & 0.18 & Filling of potholes & (A6-3) & 0.6 \\
\hline & & No proper sign boards & 0.70 & Placing of sign boards & (A6-4) & 0.3 \\
\hline & & Pot hole index & 0.18 & Filling of potholes & (A6-5) & 0.7 \\
\hline \multirow[t]{4}{*}{4} & \multirow[t]{4}{*}{ S10 } & Poor structural condition & 0.12 & Overlaying & (A10-1) & 1.0 \\
\hline & & Rut depth index & 0.10 & Filling of rut depth & (A10-2) & 1.0 \\
\hline & & No proper sign boards & 0.64 & Placing of sign boards & (A10-3) & 0.3 \\
\hline & & No proper curve & 0.27 & Providing proper curves & (A10-4) & 0.7 \\
\hline \multirow[t]{5}{*}{5} & \multirow[t]{5}{*}{ S4 } & Poor structural condition & 0.20 & Overlaying & (A4-1) & 1.0 \\
\hline & & Pot hole index & 0.17 & Filling of potholes & $(\mathrm{A} 4-2)$ & 0.4 \\
\hline & & Deep cut surfaces & 0.08 & Repair of settled surface & (A4-3) & 0.6 \\
\hline & & Pot hole index & 0.17 & Filling of potholes & (A4-4) & 0.4 \\
\hline & & No proper curve & 0.16 & Providing proper curves & $(\mathrm{A} 4-5)$ & 0.6 \\
\hline
\end{tabular}

\section{Section Importance Index $\left(\mathrm{SII}_{\mathrm{s}}\right)$}

It is proposed that condition of section importance can be evaluated using an index named as Section $\mathrm{n}$ Index $\left(\mathrm{SII}_{\mathrm{s}}\right)$. Section importance index may vary from 0.0 to 1.0 (very less important to extremely important). The $\mathrm{SII}_{\mathrm{s}}$ can be obtained by a user defined rating. The user rating for section importance of a section may depend upon, importance to community, connectivity to market center, connectivity to health center, connectivity to other district roads, etc. SII $_{\mathrm{s}}$ may be rated as 1 under extremely important condition i.e. section connecting extremely important places, etc. Table 2 presents the guidelines for user rating of rural road section importance. 
The systems of weights are introduced to reflect the contribution of each index and factors. Analytical hierarchy process (AHP) is used to determine the weight of the different priority factors. The details of weight considered for various priority factors are presented in Table 3 .

Now putting the value of weight in Eq. 2 it can be written as Eq. 5:

$\mathrm{PI}_{\mathrm{s}}=0.31 \mathrm{SCI}_{\mathrm{s}}+0.09 \mathrm{TOI}_{\mathrm{s}}+0.17 \mathrm{TSI}_{\mathrm{s}}+0.43 \mathrm{SII}_{\mathrm{s}}$

Further, to illustrate the strategy and to illustrate how strategy works, ten different sections were analyzed and details of analysis and results obtained are presented in the next section.

\section{Stage-II Strategy to Determine Priority of Maintenance Activities}

The strategy to determine maintenance priority of various activities to be carried out on rural road sections $\left(\mathrm{PI}_{\mathrm{as}}\right)$ is presented in Eq. 6:

$\mathrm{PI}_{\mathrm{as}}=\mathrm{PI}_{\mathrm{s}} \times \mathrm{SFI}_{\mathrm{iS}} \times \mathrm{ME}_{\mathrm{aS}}$

where $\mathrm{PI}_{\mathrm{s}}=$ Priority index of section $\mathrm{SSFI}_{\mathrm{iS}}=\mathrm{Sub}$ priority factor index of priority factor $\mathrm{iME}_{\mathrm{aS}}=$ Maintenance effectiveness of activity a at section SIt is to be noted that $\mathrm{PI}_{\mathrm{s}}$ can be determined as explained earlier using Eq. 5 .

\section{Evaluation of Sub Priority Factor Index $\left(\mathrm{SFI}_{\mathrm{iS}}\right)$}

The strategy proposes that on the sections prioritized in stage-I, the condition of various priority factors like $\mathrm{SCI}_{\mathrm{s}}$, $\mathrm{TOI}_{\mathrm{s}}$ and $\mathrm{TSI}_{\mathrm{s}}$ need to be evaluated in more details so that various maintenance activities to be carried out on these sections can be prioritized.

Therefore, it is required to evaluate conditions of sub priority factors affecting conditions of priority factors like $\mathrm{SCI}_{\mathrm{s}}, \mathrm{TOI}_{\mathrm{s}}$, and $\mathrm{TSI}_{\mathrm{s}}$. Strategy for evaluation of sub priority factor index $\mathrm{i}$ at section $\mathrm{S}\left(\mathrm{SFI}_{\mathrm{iS}}\right)$ are explained in Table 4 Maintenance effectiveness $\left(\mathrm{ME}_{\mathrm{aS}}\right)$ of an activity at section $\mathrm{S}$ is the effectiveness of activity $\mathrm{A}$ in improving the distress condition at section $\mathrm{S}$. $\mathrm{ME}_{\mathrm{aS}}$ can be provided as input by user (as explained in Table 8) depending upon section condition and the effectiveness of activity A in improving the distress condition at section $\mathrm{S}$.

\section{Analysis and Result using Proposed Strategy}

To illustrate the strategy, a hypothetical network of ten different road sections is analyzed. The proposed strategy consists of two stages and analysis and result for each stage is presented in following section. Detail of input data for analysis using proposed strategy is presented in Table 5.

\section{Analysis and Results for Stage I}

Stage 1 includes evaluation of priority index at ten different low volume rural road sections. The priority index $\left(\mathrm{PI}_{\mathrm{s}}\right)$ for all the ten sections was determined using Eq. 5 and it is presented in Table 6

These indices given in Table 6 were used to determine priority index of different section i.e. $\mathrm{PI}_{\mathrm{s}}$ using Eq. 5. Analysis and result for stage I shown graphically in Fig. 2

After determining $\mathrm{PI}_{\mathrm{s}}$ various sections were ranked in the order of their $\mathrm{PI}_{\mathrm{s}}$ values which are given in Table 6 . Table 6 indicated that $\mathrm{PI}_{\mathrm{s}}$ value of different section indicates the level of priority given to that section. High value of $\mathrm{PI}_{\mathrm{s}}$ indicates that higher priority should be given to that section for maintenance. Figure 2 presents the maintenance

Table 9 Analysis results for of $\mathrm{PI}_{\mathrm{as}}$ and rank of different activities

\begin{tabular}{|c|c|c|c|}
\hline S. no. & Activity & $\mathrm{PI}_{\mathrm{as}}$ & Rank \\
\hline 1 & A4-1 & 0.08084 & 9 \\
\hline 2 & A4-2 & 0.027486 & 21 \\
\hline 3 & A4-3 & 0.020129 & 24 \\
\hline 4 & A4-4 & 0.027486 & 20 \\
\hline 5 & A4-5 & 0.037833 & 18 \\
\hline 6 & A6-1 & 0.090192 & 5 \\
\hline 7 & A6-2 & 0.027058 & 22 \\
\hline 8 & A6-3 & 0.06088 & 12 \\
\hline 9 & A6-4 & 0.118377 & 3 \\
\hline 10 & A6-5 & 0.071026 & 11 \\
\hline 11 & A7-1 & 0.158953 & 1 \\
\hline 12 & A7-2 & 0.020733 & 23 \\
\hline 13 & A7-3 & 0.04112 & 17 \\
\hline 14 & A7-4 & 0.092607 & 4 \\
\hline 15 & A7-5 & 0.041466 & 16 \\
\hline 16 & A7-6 & 0.089843 & 6 \\
\hline 17 & A9-1 & 0.124366 & 2 \\
\hline 18 & A9-2 & 0.018655 & 26 \\
\hline 19 & A9-3 & 0.027643 & 19 \\
\hline 20 & A9-4 & 0.019899 & 25 \\
\hline 21 & A9-5 & 0.05653 & 13 \\
\hline 22 & A9-6 & 0.018429 & 27 \\
\hline 23 & A9-7 & 0.078011 & 10 \\
\hline 24 & A10-1 & 0.054228 & 14 \\
\hline 25 & A10-2 & 0.04519 & 15 \\
\hline 26 & A10-3 & 0.086223 & 7 \\
\hline 27 & A10-4 & 0.08446 & 8 \\
\hline
\end{tabular}

The $\mathrm{PI}_{\mathrm{as}}$ obtained for different sections are also plotted in Fig. $3 \mathrm{a}, \mathrm{b}$ with respect to the various maintenance activities 
Fig. 3 a Rank of activities $\mathrm{PI}_{\mathrm{as}}$ (rank 1-15) to be carried out at different rural road sections. b Rank of activities $\mathrm{PI}_{\mathrm{as}}$ (rank 16-27) to be carried out at different rural road sections (a)

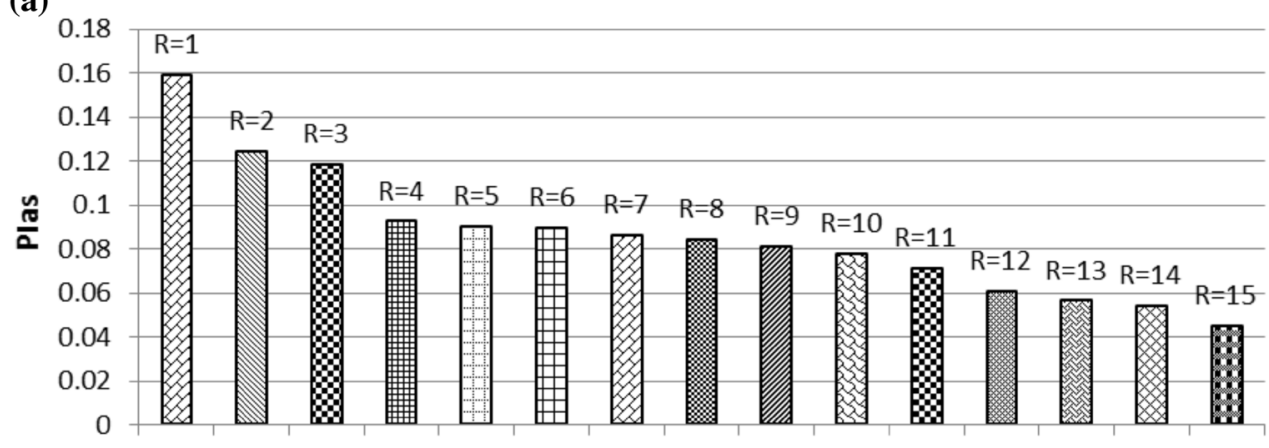

A7-1 A9-1 A6-4 A7-4 A6-1 A7-6 A10-3A10-4 A4-1 A9-7 A6-5 A6-3 A9-5 A10-1A10-2

Mantenence Activity (A)

(b)

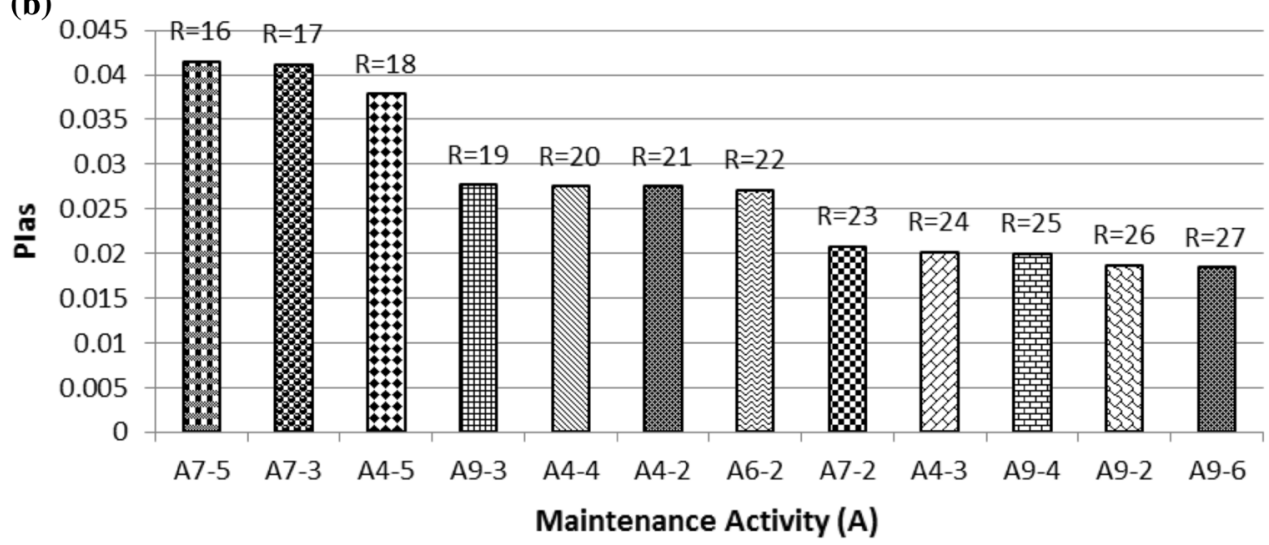

priority of section with their respective sections Ranks obtained for different section are also shown in the Fig. 2. It is clear from the Fig. 2 that Section S7 gets highest priority for maintenance. Section S7 is having highest structural condition index, traffic operation index and Section S7 is also having highest traffic safety index and section importance index.

\section{Analysis and Results for Stage II}

This section presents the analysis and result of stage II. The $\mathrm{PI}_{\mathrm{as}}$ value of five low volume rural road section whose priority index $\left(\mathrm{PI}_{\mathrm{s}}\right)$ is greater than $40 \%$ is determined by using Eq. 6. Table 7 present the details of input data of activities on road sections.

Analysis and results of stage-II for determination of condition indices is as per the strategy explained in the earlier section.

The analysis results and the values of $\mathrm{SFI}_{\mathrm{iS}}$ obtained from the above input data are given in Table 8

These indices given in Table 8 were used to determine maintenance priority of different activities i.e. $\mathrm{PI}_{\mathrm{as}}$ using Eq. 6. After determining $\mathrm{PI}_{\mathrm{as}}$ various sections were ranked in the order of their $\mathrm{PI}_{\mathrm{as}}$ value and is shown in Table 9.
The ranking of different section depends on the priority of maintenance activities $\left(\mathrm{PI}_{\mathrm{as}}\right)$ of each section. It is clear from Fig. 3a, b that activity of overlay at Sect. "Section Importance Index (SII $))$ " i.e. A7-1 ranks 1 (highest) and activity of filling potholes at Sect. "Evaluation of Sub Priority Factor Index ( $\left.\mathrm{SFI}_{\mathrm{iS}}\right)$ ") i.e. A9-6 ranks 27 (lowest). This seems to be logic as $\mathrm{PI}_{\mathrm{as}}$ value of $\mathrm{A} 7-1$ is 0.158953 (highest) while $\mathrm{PI}_{\mathrm{as}}$ value of $\mathrm{A} 9-6$ is 0.018429 (lowest). Further it is clear that A7-1 should be treated first. Strategy also says that A7-1 should be treated first and hence strategy ranks section rationally.

Analysis results indicated that proposed strategy is less time consuming simple and cost effective and can be executed with minimal data which can be obtained easily and economically from each section of a rural roads network

\section{Conclusions}

Some important conclusions drawn from this study are as follows:

- Prioritization of maintenance activities depends on several factors such as functional condition, structural 
condition and importance of different sections in the road network, etc. However, a critical review of the literature indicated that no such comprehensive strategy is available to prioritize maintenance activities for a low volume road network. Most of the methodologies are sophisticated, costly and need specialized equipment and hence not convenient to use for rural road network. Hence, there is an urgent need to develop innovative maintenance strategies focusing on rural road network which are cost effective, quick and simple.

- This study presents a two stage strategy to select the most appropriate activities to be carried out at different sections of a low volume roads network considering their priority for maintenance based on importance, present and future conditions of road section, etc. The strategy proposes that first sections which are more critical for maintenance needs to be selected in stage-I. Further, the sections identified in stage I needs to be evaluated in more detailed so that the various maintenance activities to be carried out on these sections can be prioritized. Thus, the proposed strategy will be more economical as details studies needs not to be carried out on all sections.

- A strategy is developed in stage I to determine maintenance priority of low volume road sections. A hierarchal structure is developed in stage I to identify critical factors affecting maintenance priority of rural road sections. In this stage various indices are also developed to evaluate the condition of priority factors. The strategy of stage-I proposed a priority index $\left(\mathrm{PI}_{\mathrm{s}}\right)$ to priorities the sections of low volume road network using minimal data. $\mathrm{PI}_{\mathrm{s}}$ can be used to determine the maintenance priority and to rank different sections in the road network.

- A strategy is also developed in stage II to determine priority of maintenance activities to be carried out on different low volume road sections. Stage II of this study also contributes development of priority index $\left(\mathrm{PI}_{\mathrm{as}}\right)$ of different activities to be carried out on different sections in the road network. $\mathrm{PI}_{\mathrm{as}}$ is developed considering maintenance effectiveness of activity, condition of priority factors and section priority, etc. This priority index $\left(\mathrm{PI}_{\mathrm{as}}\right)$ can be used to rank different maintenance activities to be carried out on different low volume road sections in the road network.
- The strategy proposed in this study is also illustrated with the help of example of a hypothetical rural roads network. Analysis results indicated that the proposed strategy is less time consuming simple and cost effective and can be executed with minimal data which can be obtained easily and economically from each section of a low volume roads network.

- It is expected that the strategy proposed in this study can be used for selection of appropriate maintenance activity on different low volume road section so that available resources for road maintenance can be utilized to achieve maximum improvement.

Acknowledgments The authors acknowledge the opportunity to present the research work that forms the basis of this article at the 3rd Conference of the Transportation Research Group of India held at Kolkata (India) from 1720 December, 2015

\section{References}

1. Agarwal PK, Singh AP (2010) Some strategies for sustainable maintenance of rural roads in India. Int $\mathbf{J}$ Adv Eng Technol 1(3):304-311

2. Petts, Cook, Tuan, Dzung (2005) From road surfacing problems to mainstreaming new techniques in national standard seminar: sustainable access and local resource solutions, Rural Road Research in Vietnam 28-30

3. Agarwal PK (2006) Road condition, prioritization and optimal resource allocation for highway maintenance at network level, $\mathrm{Ph}$. D. thesis, Department of Civil Engineering, IIT Kanpur

4. Aggarwal S, Jain SS, Parida M (2002) A critical appraisal of pavement management systems. IRC J Indian Roads Congr New Delhi 63(2):327-403

5. Chakrabarti S, Rawat MS, Mondal B (1995) Highway design and maintenance standard model (HDM): calibration and adoption to Indian conditions. IRC J 56(1):75-101

6. Choudhary S, Agarwal PK (2013) An innovative strategy for maintenance of highway pavement. Int J Eng Res Appl (IJERA) 3(3):54-60. http://www.ijera.com. Accessed June 2013

7. Shailendra G, Veeraragavan A (2010) Quantification of benefits of improved rural road performance due to good drainage. IRC J Vol 71(1):54-60

8. Jain SS, Gupta AK, Khanna SK, Dayanand (1996) Development of maintenance and rehabilitation investment strategy for flexible rural roads. IRC J Vol 57(2):77-99

9. Nagabhushana MN, Jain PK, Kanchan PK (2010) Innovative strategies for maintenance and rehabilitation of metropolitan city roads - a case study. Indian Rural Roads 71(2):33-43 